\title{
THE PLACE OF LIVING, SCHOOL AND FAMILY INFLLENCE ON THE PATTERN OF PHYSICAL ACTIVITY AND SEDENTARY BEHAVIOR OF ADOLESCENTS: A CROSS SECTIONAL STUDY
}

\author{
Elżbieta Cieśla, ${ }^{1, A, B, C, D, E}$ Edyta Suliga ${ }^{2}$ D, E \\ ${ }^{1}$ The Jan Kochanowski University in Kielce, Faculty of Medicine and Health Sciences, Department of the Developmental Age Research, \\ Institute of Public Health, Poland \\ ${ }^{2}$ The Jan Kochanowski University in Kielce, Faculty of Medicine and Health Sciences, Department of the Prevention of Alimentary Tract \\ Diseases, Institute of Nursing and Midwifery, Poland \\ A Study Design; ${ }^{\mathrm{B}}$ Data Collection; ${ }^{\mathrm{C}}$ Statistical Analysis; ${ }^{\mathrm{D}}$ Manuscript Preparation; ${ }^{\mathrm{E}}$ Funds Collection
}

\author{
Address for correspondence: \\ Elżbieta Cieśla \\ Jan Kochanowski University in Kielce, Institute of Public Health \\ IX Wieków Kielc 19, 25-317 Kielce, Poland \\ E-mail: eciesla@ujk.edu.pl
}

\begin{abstract}
Ahstract The aim of this study was to determine the influence of place of living, type of school, and family background on the physical activity and sedentary behavior of adolescents. 1,280 adolescents took part in the research: 694 boys and 586 girls aged 16-19 from Poland. Physical activity (PA) and sedentary behavior (SB) were evaluated by IPAQ-long version. A multiple regression analysis was used to evaluate the influence of socio-economic factors on physical activity and sedentary behavior. The results suggested a difference between boys and girls in all domains of physical activity and sedentary behavior. The results also indicated that social factors influence physical activity and sedentary behavior in different ways. After adjusting the model to BMI and age tested, the key determinants for boys' physical activity were: type of leisure time in the family and place of living, while for girls - type of school and type of leisure time in the family. Sedentary behavior of both sexes were strongly dependent on type of school, and - for boys - parents' education and type of leisure time in the family were also important. The results suggest the need for continuous monitoring of physical activity and seated behavior as well as taking into account a wide spectrum of social factors in which adolescents grow. Interventions and strategies to promote physical activity should focus on family involvement and uniting family and educational institutions operating in local environments.
\end{abstract}

Key Wordls adolescents, physical activity, sedentary behaviors, family support, place of living, type of school

\section{Introduction}

Recently, the problem of diminishing physical activity has intensified significantly. It especially concerns societies in countries with high standards of living, where the development of new information and communication technologies means that people spend less time on physical activities (Badland, Schofield, 2006; Owen et al., 2011; 
Pate, Mitchell, Byun, Dowda, 2011). Public health experts agree that the genetically determined need for physical activity, which is vital for maintaining a person's metabolic functions and health on an optimal level, has been disturbed (Tremblay, Colley, Saunders, Healy, Owen, 2010). It is a worrying phenomenon since lack of physical activity greatly influences health and costs of treatment for entire societies. Deficiency or lack of physical activity favors the development of overweight and obesity, as well as other chronic diseases which are Non Communicable Diseases, including the cardiovascular system and metabolic diseases, strokes and certain carcinomas (Janssen, LeBlanc, 2010; Reiner, 2013). A high level of sedentary behavior accounts for over 3 million preventable deaths, as a result influencing the quality of life and life expectancy (Owens, Crone, James, 2013).

The habit to spend leisure time in an active way often forms in childhood and most frequently in adolescence (Van der Horst, Paw, Twisk, Van Mechelen, 2007). If such habits are formed early, it usually means that physical activities are continued in later life. Not only is the level of physical activity formed by individual traits but also the environment we live in. The influence of the environment is on two main micro levels (the family and peers) and macro levels (among others: support of institutions and place of living) (Katzmarzyk et al., 2008). Their scope and the effects of influence may be independent or in synergy, so the evaluation of their influence and the strength of associations are complicated problems and impossible to be explained explicitly, which is confirmed by varied results of studies to date. Since the conditions of the environment are changing dynamically, they must be constantly monitored. In this way not only may we understand the interrelations and the mechanism of their changes better, but also develop better strategies of action adapted to different age groups, which will eventually lead to a fitter society, less susceptible to the numerous consequences of a sedentary lifestyle (Solomon, Rees, Ukoumunne, Metcalf, Hillsdon, 2013).

Many authors suggest that the key to understanding the influence of the environment on physical activity is the fast development of urbanization. It is usually accompanied by demographic, economic, social and ecological changes, as well as changes in the pattern of behavior in people with consequences for health, which are difficult to predict (Report ICSU, 2011). Some of the significant advantages of the urban environment in comparison with the rural environment, are better access to education and health care, as well as better facilities to organize more interesting leisure time activities, both active and inactive (Vlahov, Galea, 2002; Machado-Rodriques et al., 2014). Other potential factors such as: stress, air pollution, safety, fast pace of life and the system of city communication may be, in theory, risk factors of sedentary behavior and lower physical activity (Vlahov, Galea, 2002; Vlahov et al., 2007). It is not surprising though that it was often assumed that city dwellers frequently demonstrated a lower potential for physical activity and a higher potential for sedentary behaviors in comparison with dwellers of rural areas. Such assumption is supported by results of certain research (Albarwani, Al-Hashmi, Al-Abri, Jaju, Hassan, 2009; Springer, Hoelscher, Castrucci, Perez, Kelder, 2009). However, most research lead to opposite conclusions, proving that there is a significantly higher level of physical activity in adolescents from urban areas than in adolescents from rural areas (Kristjansdottir, Vilhjalmsson, 2001; Machado-Rodriques et al., 2014). The influence of the place of living is not only limited to linking the place of living to physical activity. The influence of access to playgrounds, extra-curricular sports activities, preferred means of transport, the neighborhood etc. on physical activity are well known (Davison, Lawson, 2006).

There is much research that describe the influence of family background on the physical activity of children and adolescents. The economic situation, parental educational level, support from the closest family given during 
the process of learning motor skills and physical activities, as well as forming a proper attitude towards their own health, seem to have a significant in fluence on PA and SB (Lasheras, Aznar, Merino, Lopez, 2001; Van der Horst et al., 2007). Studies demonstrate that a higher level of education of parents and SES has a significant influence on a higher level of physical activity in adolescents (Finger, Mensink, Banzer, Lampert, Tylleskär, 2014). Moreover, it has been observed that parents' physical activity, especially that of the fathers, as well as spending leisure time together, involvement in children's sports training and transporting children to training and other physical activities, has a positive effect on the probability of long term involvement of children and adolescents in sports and recreational activities (O'Connor, Jago, Baranowski, 2009; Beets, Cardinal, Alderman, 2010). Definitely less attention has been dedicated to the school environment, especially in regards to adolescents. While it does not raise doubts that there is higher level of physical activity in private schools than in state schools, the findings by K. Van der Horst et al. (2009) were surprising. They noticed a varied influence of different types of state schools on PA and SB. The process of forming attitudes towards different forms of physical activity seems to be inextricably linked with the system of physical exercise and sports included in syllabuses in all types of schools and on every level of education. Negative habits towards health and lower level of PA as well as more frequent sedentary behaviors are usually more characteristic for vocational school students rather than grammar school students (Van der Horst et al., 2009). This phenomenon intensifies with age and is more typical for girls than for boys (Huang, Schnaub, Gross, John, Mayer, 2013). It was observed that there was a higher percentage of students from vocational schools and technical high schools who do not know the optimal time for daily moderate and intensive physical activity, and sedentary behaviors recommended by WHO and pediatricians (Loucaides, Jago, Theophanous, 2011).

Study results regarding the above-mentioned problems of physical activity factors clearly suggest a significant influence of all elements of the environment we live in on physical activity and sedentary behaviors. While the importance of family, school and place of living is understandable in regard to children and younger adolescents, it is more unclear and more difficult to interpret their connection with PA in regard to older adolescents.

Moreover, most studies focus on analyzing individual social or economic factors and not many studies consider the importance of many environmental factors and their influence on PA. Hence, the aim of this work is to analyze the associations between the place of living, school, family (parental educational level), habits regarding spending leisure time together and preferred ways of spending free time, and physical activity and sedentary behaviors in adolescents aged $16-19$.

\section{Material and methods}

The procedure of this study was accepted by the bioethical committee of the Jan Kochanowski University's Faculty of Health Sciences (10/2015). Students aged 16-19 from grammar schools, technical high schools and vocational schools from the Świętokrzyskie Voivodeship participated in this study, which was conducted from 26 March 2015 to 26 April 2015. 1,280 students, 694 boys and 586 girls, took part in this study. Detailed characteristics of the participants in terms of family background, the type of school and place of living are shown in Table 1. This study constitutes as a part of a broader study on physical activity of adolescents and young adults aged 15-25 from the Świętokrzyskie Voivodeship (Poland).

Schools for this study were selected by stratified sampling. Schools were drawn taking into account two strata. The first stratum was the environment of the school: a big town or city (more than 100,000 residents), and a medium or small town (less than 100,000 residents). The second stratum was the type of school: grammar schools, technical 
high schools and vocational schools. The research was mainly done by the authors but the management in three schools did not agree to this procedure so the questionnaires were handled by fully trained PE teachers.

\section{Evaluation of physical activity}

The participants self-reported their own physical activity from the previous week by means of the International Physical Activity Questionnaire-long version (IPAQ, 2012). The IPAQ has been evaluated in 14 studies and found to have good test-retest reliability and a modest Spearman correlation $(r=0.30)$ with PA measured by accelerometer (Craig et al., 2003). The IPAQ captures activity information on walking, moderate-intensity, and vigorous-intensity activities. The total general physical activity was calculated by summing time in minutes and its frequency in days for all forms of physical activity. Different forms of activity e.g. moderate, vigorous walking were calculated by weighing each type of activity by its energy needs, defined in METs (multiples of resting metabolic rate). Sedentary behavior during last week was determined on a basis of time spent in a sitting position on weekdays and weekends. Next the average number of hours a day was calculated (IPAQ, 2012).

\section{Evaluation of physical development}

Based on Seca 213 body height measurement and Seca 799 electronic weight, BMI values were calculated according to BMl formula: body mass $(\mathrm{kg}) /$ body height $(\mathrm{m})^{2}$.

\section{Demographic data}

Data regarding the place of living of the participants were also collected. The distinction of place of living into rural and urban areas was done according to the classification of the Central Statistical Office of Poland. Two categories of towns were distinguished: towns with more than 100,000 inhabitants and those with less than 100,000 inhabitants. Rural areas were defined as areas where the density of the population was lower than 150 people per $\mathrm{km}^{2}$, or the number of inhabitants lower than 5,000 (Statistical Yearbook, 2013). Parental educational level, separately for the mother and the father, was classified according to the official Polish system of levels of education (Czapiński, Panek, 2014). The 4 levels of education are: elementary education or not completed elementary education, vocational education, secondary education, higher education. There were three types of school that the adolescents attended: 3-year-long grammar schools, 4-year-long technical high schools and 3-year-long vocational schools. The role of the family in encouraging physical activity was determined by two categories: the preferred way of spending free time together with the family (active, passive) and habits regarding spending free time (together with the family or separately). In order to determine age with 0.01 margin, the adolescents were asked about their date of birth. The questionnaires were filled in by the participants of the study.

\section{Statistical analysis}

The data collected were analyzed statistically by means of the Statistica 10.0 software. For quality variables the percentage was calculated, separately for each sex and the power of associations was calculated using nonparametric Chi-squared test.

In the case of quantity features: age, BMI [kg/(m)2], total, moderate, vigorous PA (MET/min/day) and sedentary behavior (hours/day), distribution was verified by Kolmogorov-Smirnov test. Basic statistical characteristics were 
calculated: means, standard deviation, medians and Q1-Q3 (interquartile range). T Student test was used in order to determine differences between both sexes in age, body height, body mass and BMI. U Mann-Whitney test was used to evaluate the difference between boys' PA and girls' PA in their particular aspects: moderate, vigorous, walking PA, total PA and sedentary behaviors.

In order to estimate the influence of given environmental variables on the level of physical activity expressed in MET, a multiple regression analysis was conducted. The following variables were taken into consideration in each model: place of living ( 1 - urban, 0 - rural), the type of school the participants attend ( 1 - grammar school, 2 - technical high school, 3 - vocational school). Following E. Korzeniowska and K. Puchalski's (2010) suggestion, a minimum high school education of parents, separately for mother and father, was recognized as a significant factor of health awareness of the parents. Thus, a dichotomous division of their level of education was included in the analysis: elementary and vocational -0 , high school and college -1 . The model also took into account habits concerning mutual leisure time ( 0 - together with the family, 1 - not with the family), and the preferred way of spending leisure time (1 - active, 0 - passive). Transformation of PA values in each aspect and sedentary behaviors into natural logarithms was used. Each model was adjusted to age and BMI. Statistically significant values for each calculated parameter were determined at $p \leq 0.05$.

\section{Results}

Boys had a significantly higher body height, body mass and BMI than girls (respectively: $178.90 \pm 7.03 \mathrm{~cm}$ vs. $166.14 \pm 6.96 \mathrm{~cm} ; p<0.001 ; 71.10 \pm 10.90 \mathrm{~kg}$ vs. $56.77 \pm 6.06 \mathrm{~kg} ; p<0.001 ; 21.87 \pm 3.58 \mathrm{~kg} / \mathrm{m}^{2} \mathrm{vs} .20 .28 \pm 3.66 \mathrm{~kg} / \mathrm{m}^{2} ;$ $p<0.001$ ). There were no significant differences in the age of the subjects (boys: $17.77 \pm 1.06$; girls: $17,76 \pm 1.02$; $p=0.977)$.

More than half of the participants of this study lived in rural areas (Table 1). Girls lived in the country more often than boys. On the other hand, more boys lived in towns with more than 100,000 inhabitants and cities $(p \leq 0.01)$. More than $69 \%$ of the participants declared that the most common way of spending leisure time in their families is in a passive way. It was significantly more frequent among girls than among boys $(p \leq 0.05)$. Relations between parental educational level, their habits of spending leisure time together and the sex of the participant were statistically insignificant $(p \leq 0.01)$.

Table 1. Family background, type of school and place of living of the participants

\begin{tabular}{|c|c|c|c|}
\hline \multirow[t]{2}{*}{ Environmental variables } & $\begin{array}{c}\text { Boys } \\
(\mathrm{N}=698)\end{array}$ & $\begin{array}{c}\text { Girls } \\
(N=592)\end{array}$ & Total $(\mathrm{N}=1290)$ \\
\hline & $\mathrm{N}(\%)$ & $\mathrm{N}(\%)$ & $\mathrm{N}(\%)$ \\
\hline 1 & 2 & 3 & 4 \\
\hline \multicolumn{4}{|c|}{ Place of living $(p \leq 0.01)$} \\
\hline Rural & $133(19.05)$ & $68(11.49)$ & $201(15.58)$ \\
\hline Urban $<100$ thousand habitants & $146(20.92)$ & $136(22.97)$ & $282(21.86)$ \\
\hline Urban $\geq 100$ thousand habitants & $397(56.88)$ & $380(64.19)$ & $777(60.23)$ \\
\hline Missing data & $22(3.15)$ & $8(1.35)$ & $30(2.33)$ \\
\hline \multicolumn{4}{|c|}{ Type of school $(p \leq 0.001)$} \\
\hline Grammar school & $151(21.63)$ & $322(54.39)$ & $473(36.66)$ \\
\hline Technical high school & $450(64.47)$ & $242(40.88)$ & $692(53.64)$ \\
\hline Vocational school & $97(13.90)$ & $28(4.73)$ & $125(9.70)$ \\
\hline
\end{tabular}




\begin{tabular}{|c|c|c|c|}
\hline 1 & 2 & 3 & 4 \\
\hline \multicolumn{4}{|c|}{ Mother's education $(p \leq 0.001)$} \\
\hline Elementary & $53(7.59)$ & $60(10.14)$ & $113(8.76)$ \\
\hline Vocational & $210(30.08)$ & $220(37.16)$ & $430(33.33)$ \\
\hline High school & $254(36.39)$ & $214(36.15)$ & $468(36.28)$ \\
\hline College & $173(24.78)$ & $90(15.20)$ & $263(20.39)$ \\
\hline Missing data & $8(1.16)$ & $8(1.35)$ & $16(1.24)$ \\
\hline \multicolumn{4}{|c|}{ Father's education $(p \leq 0.001)$} \\
\hline Elementary & $56(8.02)$ & $52(8.78)$ & $108(8.37)$ \\
\hline Vocational & $285(40.83)$ & $308(52.03)$ & $593(45.97)$ \\
\hline High school & $237(33.95)$ & $173(29.22)$ & $410(31.78)$ \\
\hline College & $114(16.33)$ & $46(7.77)$ & $160(12.41)$ \\
\hline Missing data & $6(0.87)$ & $13(2.19)$ & $19(1.47)$ \\
\hline \multicolumn{4}{|c|}{ Preferred way of spending leisure time in the family $(p \leq 0.05)$} \\
\hline Passive & $457(65.47)$ & $429(72.47)$ & $886(68.68)$ \\
\hline Active & $211(30.23)$ & $147(24.83)$ & $358(27.75)$ \\
\hline Missing data & $30(4.30)$ & $16(2.70)$ & $46(3.57)$ \\
\hline \multicolumn{4}{|c|}{ Habits of spending leisure time (n.s) } \\
\hline Family spend leisure time together & $373(53.44)$ & $310(52.37)$ & $683(52.95)$ \\
\hline Family don't spend leisure time together & $304(43.55)$ & $275(46.45)$ & $579(44.88)$ \\
\hline Missing data & $21(3.01)$ & $7(1.18)$ & $28(2.17)$ \\
\hline
\end{tabular}

Source: authors' own elaboration.

Energy expenditure connected with total PA during a day was significantly higher in boys than in girls, on average by $295.75 \mathrm{MET} / \mathrm{min} /$ day (Table 2). For moderate PA it was usually $145.25 \mathrm{MET} / \mathrm{min} /$ day, and for vigorous $\mathrm{PA} 160.37 \mathrm{MET} / \mathrm{min} /$ day. While in girls it was on average $0.92 \mathrm{MET} / \mathrm{min} /$ day more on sedentary behaviors than in boys. Differences between sexes in walking PA were not statistically significant.

Table 2. Physical activity (MET/min/day) and sedentary behavior (hrs/day) in adolescents

\begin{tabular}{|c|c|c|c|c|c|}
\hline \multirow{2}{*}{$\mathrm{PA}$ and $\mathrm{SB}$} & \multicolumn{2}{|c|}{ Boys } & \multicolumn{2}{|c|}{ Girls } & \multirow{2}{*}{ p } \\
\hline & $\bar{x} ;$ sd & Me; Q1-Q3 & $\overline{\mathrm{x}} ; \mathrm{sd}$ & Me; Q1-Q3 & \\
\hline Total PA & $\begin{array}{l}1,916.07 \\
1,313.54\end{array}$ & $\begin{array}{c}1,686.00 \\
918.00-2,671.29\end{array}$ & $\begin{array}{l}1,620.32 \\
1,109.13\end{array}$ & $\begin{array}{c}1,395.86 \\
815.71-2,258.14\end{array}$ & $\leq 0.001$ \\
\hline Walking PA & $\begin{array}{l}491.95 ; \\
402.03\end{array}$ & $\begin{array}{c}396.00 \\
274.29-1,114.29\end{array}$ & $\begin{array}{l}501.83 \\
399.92 \\
\end{array}$ & $\begin{array}{c}414.86 ; \\
169.71-735.43 \\
\end{array}$ & n.s \\
\hline Moderate PA & $\begin{array}{l}779.93 \\
685.89\end{array}$ & $\begin{array}{c}600.00 \\
274.29-1,114.29\end{array}$ & $\begin{array}{l}634.68 \\
523.38\end{array}$ & $\begin{array}{c}520.00 \\
257.14-882.86\end{array}$ & $\leq 0.01$ \\
\hline Vigorous PA & $\begin{array}{l}644.19 \\
563.14 \\
\end{array}$ & $\begin{array}{c}537.14 \\
171.43-1,028.57\end{array}$ & $\begin{array}{l}483.82 \\
494.13 \\
\end{array}$ & $\begin{array}{c}325.71 \\
102.86-771.43\end{array}$ & $\leq 0.001$ \\
\hline Sedentary behavior & $\begin{array}{l}4.79 \\
2.83\end{array}$ & $\begin{array}{c}4.79 ; \\
2.71-7.00\end{array}$ & $\begin{array}{l}5.43 \\
2.91\end{array}$ & $\begin{array}{c}5.71 ; \\
3.43-7.86\end{array}$ & $\leq 0.001$ \\
\hline
\end{tabular}

Source: authors' own elaboration.

Regressive analysis allowed us to distinguish important predicators for various physical activities in adolescents (Table 3). The percentage of explaining the total variability of different aspects of PA and SB by factors taken into 
consideration in regressive analysis fluctuated in boys between $1.54 \%$ in case of total PA and $6.48 \%$ regarding SB (Table 3). In girls $\mathrm{R}^{2}$ was on similar level, from $2.45 \%$ for walking PA and to $4.59 \%$ for vigorous PA (Table 4 ).

Table 3. Evaluation of parameters for the regressive analysis model - boys ${ }^{A}$

\begin{tabular}{|c|c|c|c|c|c|}
\hline \multirow[t]{2}{*}{ Independent variables list } & \multicolumn{5}{|c|}{$\begin{array}{l}\text { Dependent variables } \beta \\
(95 \% \mathrm{Cl}) \mathrm{p}\end{array}$} \\
\hline & sedentary behaviors & walking PA & moderate PA & vigorous $\mathrm{PA}$ & total PA \\
\hline \multirow{3}{*}{ Type of school ${ }^{1}$} & -0.140 & -0.053 & 0.054 & 0.113 & -0.030 \\
\hline & $(-0.226-(-0.054))$ & $(-0.138-0.032)$ & $(-0.028-0.137)$ & $(0.024-0.203)$ & $(-0.115-0.056)$ \\
\hline & 0.01 & ns & ns & 0.05 & ns \\
\hline \multirow{3}{*}{ Mother's education² } & -0.145 & 0.015 & -0.007 & -0.032 & -0.016 \\
\hline & $(-0.243-(-0.047))$ & $(-0.081-0.111)$ & $(-0.101-0.087)$ & $(-0.133-0.068)$ & $(-0.113-0.081)$ \\
\hline & 0.01 & ns & ns & ns & ns \\
\hline \multirow{3}{*}{ Father's education ${ }^{2}$} & 0.153 & -0.004 & -0.003 & -0.027 & 0.036 \\
\hline & $(0.053-0.254)$ & $(-0.101-0.093)$ & $(-0.089-0.093)$ & $(-0.129-0.074)$ & $(-0.062-0.135)$ \\
\hline & 0.01 & ns & ns & ns & ns \\
\hline \multirow{3}{*}{ Place of living ${ }^{3}$} & 0.069 & 0.107 & -0.095 & -0.018 & 0.011 \\
\hline & $(-0.019-0.157)$ & $(0.020-0.193)$ & $(-0.179-00.010)$ & $(-0.109-0.072)$ & $(-0.076-0.098)$ \\
\hline & Ns & 0.05 & 0.05 & ns & ns \\
\hline \multirow{3}{*}{ Type of leisure time in family ${ }^{4}$} & -0.169 & 0.116 & 0.090 & 0.120 & 0.106 \\
\hline & $(-0.253-(-0.084))$ & $(0.033-0.200)$ & $(0.008-0.179)$ & $(0.033-0.207)$ & $(0.021-0.190)$ \\
\hline & 0.001 & 0.01 & 0.05 & 0.01 & 0.05 \\
\hline \multirow{3}{*}{ The habits of leisure time in family ${ }^{5}$} & 0.043 & -0.026 & -0.142 & 0.035 & -0.108 \\
\hline & $(-0.042-0.127)$ & $(-0.110-0.058)$ & $(-0.224-0.172)$ & $(-0.053-0.122)$ & $(-0.192-(-0.023))$ \\
\hline & Ns & ns & 0.001 & ns & 0.05 \\
\hline \multirow{2}{*}{$\mathrm{R}^{2}(\mathrm{p})$} & 0.0648 & 0.0194 & 0.0365 & 0.0165 & 0.0154 \\
\hline & $(0.001)$ & $(0.01)$ & $(0.001)$ & $(0.05)$ & $(0.05)$ \\
\hline
\end{tabular}

A model adjusted for BMI and age; ${ }^{1} 0$ - grammar school; 1 - technical high school; 2 - vocational school; ${ }^{2} 0$ - elementary, vocational education; 1 - high school, college education; ${ }^{3} 0$ - rural; 1 - urban; ${ }^{4} 0$ - active; 1 - passive; ${ }^{5} 0$ - leisure time together; 1 - leisure time separately.

Source authors' own elaboration.

The type of school the boys taking part in this study attended demonstrated a positive connection with vigorous PA, and negative with sedentary behaviors (Table 3). Students of vocational schools expended more energy on physical activity and less on sedentary behaviors than their peers from technical high schools and grammar schools. The way of spending leisure time in the family was important for the type and intensity of physical activity in boys. It had positive correlation with total, vigorous and moderate PA and walking PA (respectively: $\beta=0.106 ; \beta=0.20$; $\beta=0.09 ; \beta=0.107$ ), and negative with sedentary behaviors $(\beta=-0.169)$. Active leisure time preferred by the family resulted in expending more energy on physical activity than on sedentary behaviors. Habits regarding spending leisure time together with the family has negative influence on moderate and total PA (respectively: $\beta=-0.142$; $\beta=-0.108)$. No habit of spending leisure time together in the family had negative influence on physical activity.

The place of living had a positive correlation with walking PA $(\beta=0.107)$ and negative with moderate PA $(\beta=-0.095)$. An urban environment was in favor of activities connected with walking but influenced a lower expenditure of energy on moderate PA.

Parental educational level was significantly connected with sedentary behaviors. The higher the education of the mother $(\beta=-0.145)$, the less time the male participants of this study devoted to sedentary behaviors, however, in case of the fathers, this correlation was positive $(\beta=0.153)$. 
Significant predicators of physical activity in girls were the type of school they attended and preferred way of spending leisure time in the family (Table 4). In case of walking PA, a significant influence of place of living and habits of spending leisure time together with the family was observed.

Tahle 4. Evaluation of parameters for the regressive analysis model - girls $^{A}$

\begin{tabular}{|c|c|c|c|c|c|}
\hline \multirow[t]{2}{*}{ Independent variables list } & \multicolumn{5}{|c|}{$\begin{array}{l}\text { Dependent variables } \beta \\
(95 \% \mathrm{Cl}) \mathrm{p}\end{array}$} \\
\hline & sedentary behaviors & walking PA & moderate PA & vigorous $\mathrm{PA}$ & total PA \\
\hline \multirow{3}{*}{ Type of school ${ }^{1}$} & -0.174 & 0.122 & 0.095 & 0.177 & 0.102 \\
\hline & $(-0.266-(-0.082))$ & $(0.032-0.212)$ & $(0.007-0.183)$ & $(0.081-0.273)$ & $(0.012-0.191)$ \\
\hline & 0.001 & 0.01 & 0.05 & 0.001 & 0.05 \\
\hline \multirow{3}{*}{ Mother's education ${ }^{2}$} & -0.022 & -0.022 & 0.025 & -0.037 & -0.003 \\
\hline & $(-0.123-0.079)$ & $(-0.122-0.078)$ & $(-0.073-0.124)$ & $(-0.145-0.072)$ & $(-0.103-0.097)$ \\
\hline & ns & ns & ns & ns & $\mathrm{ns}$ \\
\hline \multirow{3}{*}{ Father's education ${ }^{2}$} & -0.049 & -0.061 & 0.056 & 0.076 & 0.027 \\
\hline & $(-0.149-0.051)$ & $(-0.160-0.078)$ & $(-0.041-0.152)$ & $(-0.031-0.182)$ & $(-0.071-0.125)$ \\
\hline & ns & ns & ns & ns & ns \\
\hline \multirow{3}{*}{ Place of living ${ }^{3}$} & 0.007 & 0.093 & -0.010 & -0.017 & 0.051 \\
\hline & $(-0.084-0.097)$ & $(0.006-0.181)$ & $(-0.096-0.077)$ & $(-0.112-0.077)$ & $(-0.037-0.139)$ \\
\hline & Ns & 0.05 & ns & ns & ns \\
\hline \multirow{3}{*}{ Type of leisure time in family ${ }^{4}$} & -0.051 & 0.040 & 0.123 & 0.143 & 0.145 \\
\hline & $(-0.141-0.038)$ & $(-0.048-0.128)$ & $(0.036-0.210)$ & $(0.049-0.237)$ & $(0.057-0.232)$ \\
\hline & $\mathrm{ns}$ & $\mathrm{ns}$ & 0.01 & 0.01 & 0.01 \\
\hline \multirow{3}{*}{$\begin{array}{l}\text { The habits of leisure time in } \\
\text { family }\end{array}$} & 0.056 & -0.092 & -0.058 & -0.005 & -0.074 \\
\hline & $(-0.033-0.145)$ & $(-0.180-(-0.005))$ & $(-0.144-0.028)$ & $(-0.098-0.089)$ & $(-0.161-0.012)$ \\
\hline & ns & 0.05 & ns & ns & ns \\
\hline \multirow{2}{*}{$R^{2}(p)$} & 0.0343 & 0.0245 & 0.0251 & 0.0459 & 0.0299 \\
\hline & $(0.001)$ & $(0.01)$ & $(0.01)$ & $(0.001)$ & $(0.01)$ \\
\hline
\end{tabular}

${ }^{A}$ adjusted for age and BMI; ${ }^{10}$ - grammar school; 1 - technical high school; 2 - vocational school; ${ }^{2} 0$ - elementary, vocational education; 1 - high school, college education; ${ }^{3} 0$ - rural; 1 - urban; ${ }^{4} 0$ - active; 1 - passive; ${ }^{5} 0$ - leisure time together; 1 - leisure time separately.

Source: authors' own elaboration.

Female students of vocational schools expended significantly more energy on each form of physical activity in comparison with female students from technical high schools and grammar schools (respectively: $\beta=0.122$; $\beta=0.095 ; \beta=0.177 ; \beta=0.102)$, and less energy on sedentary behaviors $(\beta=-0.174)$. A preference by the family of an active way of spending leisure time encouraged a higher level of physical activity. The girls taking part in this study expended more energy on moderate, vigorous and total PA (moderate: $\beta=0.123$; vigorous: $\beta=0.143$; total PA: $\beta=0.145)$. While in families that prefer spending leisure time together $(\beta=-0.092)$ and in the urban environment ( $\beta=0.093)$, a higher level of physical activity connected with walking PA was observed.

\section{Disciussion}

This study, based on multiply analysis, presents a complex approach to determining the most important predicators of physical activity and sedentary behaviors based on three variables: place of living, the type of school adolescents attend, and family background. In accordance with previous studies, the male participants were more active in every aspect of PA (Azevedo et al., 2007; Belcher et al., 2010; Vašíčková, Groffik, Frömel, Chmelík, Wasowicz, 2013). The observed disproportions in the level of PA in relation to the sex of the participants resulted 
first of all from the context of the form of PA, its intensity and the accepted social behavior patterns. Generally, girls preferred going for walks, riding a bicycle or other activities of moderate intensity while boys preferred activities of moderate or high intensity and of a typically sports character (Van der Horst et al., 2007; Cadogan, Keane, Kearney, 2014). Due to this pattern, males can maintain a higher value of PA on each stage of development (Telama, Yang, Hirvensalo, Raitakari, 2006).

The results of this study regarding the influence of environmental factors on PA in late adolescence show that the type of school is important. In both sexes expenditure of energy on vigorous PA, as well as walking PA, moderate and total PA in girls, was higher in students of vocational schools and technical high schools than in students from grammar schools. Moreover, a lower level of SB in students of vocational schools and technical high schools was observed. Results of the study conducted by M. Aarnio et al. (Aarnio, Kujala, Kaprio, 1997; Aarnio, Winter, Kujala, Kaprio, 2002) demonstrate that a higher level of physical activity was closely connected with attending grammar schools rather than technical high schools or vocational schools. The association is especially evident in boys. C.A. Loucaides et al. (2011) pointed out that the percentage of physically active adolescents was at its lowest in technical and vocational schools, especially in girls. The knowledge of recommended time for sedentary behaviors was also poorer in technical and vocational schools. According to A.M. Jones, N. Rice and P.R. Dias (2012), the connection of positive healthy behaviors with grammar schools most probably results from criteria playing a decision making role in choosing the school. Achieving academic competency earlier is a key factor in choosing the school and future career (Hill et al., 2004). A connection between academic results and healthy behaviors was proven as well. A lower number of risky behaviors was connected with a higher level of academic competency (Bryant, Schulenberg, Bachman, O'Malley, Johnston, 2000; Tammelin, Näyhä, Laitinen, Rintamäki, Järvelin, 2003), as well as higher physical activity (Delisle, Werch, Wong, Bian, Weiler, 2010). Thus, adolescents with high school competence and most likely a high awareness of healthy behaviors usually attend grammar schools (Echols, Willms, 1995; Green, Navarro-Paniagua, Ximénez-De-Embún, Mancebón, 2014), whereas adolescents who do not satisfy these criteria attend vocational schools. An analysis of data collected in Poland by 'Health Behavior in Schoolaged Children: A WHO Collaborative Cross-National Study' also confirmed that lack of physical activity was more frequent in students of vocational schools rather than students of schools of other types (Jodkowska, Oblacińska, Mikiel-Kostyra, Tabak, 2012). As we can see, the results of our study are contrary to results of studies to date.

Additionally, calculated differences in activity that take into account the factors of sex and place of living, demonstrated in individual domains significant statistical differences in activity connected with school and work, between students from vocational schools and grammar schools (87.45 vs. 68.64; $p<0.01$ ), moving around (42.94 vs. $31.17 ; p<0.01)$, household physical activities $(3,464.05$ vs. $2,158.62 ; p<0.001)$. Whereas type of school and sex factors demonstrated that adolescents from urban areas are significantly more active in the domain of additional activities in comparison with their peers from rural areas. $(3,475.27$ vs. $3,066.88 ; p<0.05)$. On the other hand, adolescents from rural areas expend much more energy on household physical activities $(2,673.34$ vs. $2,221.96 ; p<0.01$ ). Studies conducted in Poland show that $32.2 \%$ of boys and $19.2 \%$ of girls from rural areas devote at least one hour a day to work on their parents' farm, which additionally increases their energy expenditure (Lachowski, Zagórski, 2011; Lachowski, 2013). It seems that the phenomenon described above appears on a large scale among the participants of this study who come from typical agricultural regions. The results did not show significant differences in activity regarding place of living in girls, but in boys a confirmation of this phenomenon may be a significantly higher expenditure of energy on moderate PA in rural areas than in urban areas. Another 
explanation of higher PA among students of vocational schools and technical high schools in comparison with students from grammar schools may be the fact that the former group serves apprenticeship in companies which usually means physical activity of a different degree of intensity. Moreover, parents from rural areas less often have a higher education than parents from urban areas ( $8 \%$ of fathers with higher education in rural areas vs. $20.1 \%$ in urban areas and respectively $26.2 \%$ vs. $31.1 \%$ in mothers). $61.9 \%$ of fathers from rural areas have elementary or vocational education vs. $43.8 \%$ in urban areas. Among mothers, $48.7 \%$ of mothers from rural areas have elementary or vocational education vs. $20.9 \%$ of mothers from urban areas. The factor that significantly limits spontaneous physical activity in children and adolescents who have parents with higher level of education and higher SES may be the higher number of hours devoted to extra-curricular classes and tutorials (Suliga, 2010). A strong focus on good academic results can be observed in parents with a higher level of education and in families with higher SES, which results in organizing such classes for children (e.g. tutorials from school subjects, foreign language classes etc.). It may be assumed that this phenomenon will mainly concern students of grammar schools. Whereas a more liberal attitude of parents towards upbringing, which usually occurs in families with low SES and with a lower level of education of parents may be in favor of more freedom of choice, more possibilities for spontaneous physical activity and in this way it may compensate for more extra-curricular sports activities observed in children and adolescents from families with higher SES, more frequently attending grammar schools. As a consequence, it can be assumed that lower socio-economic status of families from rural areas influenced the PA results regarding the type of school the students attended.

Studies to date mostly emphasize a positive influence of big urbanized areas on PA (Machado-Rodriques et al., 2014). Higher physical activity is possible due to better planned layout of an urban area than a rural area, including: access to public communication, closer location of shops, work, friends etc., which may induce other forms of actively moving around. Moreover, due to large-scale campaigns promoting health by physical activity, the number of all-year-round sports facilities available for the general public is definitively bigger in towns and cities than in the country, which enables more varied forms of physical activity in towns and cities. The results of this study show that only walking PA in both sexes confirms the results of previous studies that there is a positive influence of urban environment on physical activity. Higher energy expenditure on moderate PA was observed in boys from rural areas, and in other cases there were not statistically significant differences in PA. Other studies conducted in Poland showed that place of living did not differentiate the level of total PA (Bergier, Bergier, Paprzycki, 2014). It was only observed that adolescents from rural areas did more moderate and vigorous PA and adolescents from urban areas - more walking PA. Árnadóttir (2010) studied older people and she concluded that the total PA was the same for people from rural and urban areas. Yet rural females received the highest scores of all in household physical activity while rural males were more physically active than the others in the work-related domain. Physical activity in leisure time was more common in urban societies than in rural societies, though. Thus, the differences of physical activity in separate domains that we discussed previously support the results above. Moreover, Świętokrzyskie voivodeship is one of 3 voivodeships in Poland with the lowest standards of living, it is also one of the poorest regions of the European Union (http://ec.europa.eu/eurostat, 2015). Then, it is possible that sports facilities in towns and cities of this voivodeship are not as developed as in urbanized areas in other European countries and they do not create equally good opportunities to engage in physical activity. Researchers of physical activity in regions with low GDP per capita should take this into consideration when analyzing separate domains of PA. If only PA in leisure time is analyzed, the total level of PA may be underestimated. However, if we only analyze total PA, we overlook 
many data about its structure. Moreover, this analysis shows that it is possible to utilize different means to fulfill recommendation regarding physical activity in different environments.

Studies of many authors pointed out that parental educational level has a vital influence on the level of physical activity and sedentary behaviors in adolescents (Kantomaa, Tammelin, Näyhä, Taanila, 2007; Elinder, Heinemans, Zeebari, Patterson, 2014; Finger et al., 2014). High level of education of both parents has a positive influence on active participation in extra-curriculum physical activities organized by sports clubs. It concerns children of both sexes in younger age groups (Finger et al., 2014) and slightly older female participants of the studies (Kantomaa et al., 2007; Elinder et al., 2014). A study done in 7 European countries showed that parental educational level (PEL) was directly associated with children's PA only in Greek and Spanish girls' and boys' PA in Norway, and parental education level was also directly associated with PA in Hungarian boys (Jimenez-Pavon et al., 2012). In our study, we only observed a significant association of parental educational level and sedentary behaviors in boys. The lack of a significant influence of this factor on PA in adolescents may have several causes. It is probable that parental educational level does not have a vital influence on parents' income. Thus, material support of children's physical activity is comparable in families of different levels of education. Another explanation of this phenomenon is the fact that with age the influence of parents on the physical activity of their children gradually becomes lower (Alderman, Benham-Deal, Jenkins, 2010). The first symptom of this phenomenon may be the lower influence of parental educational level, which as a factor is more significant in the first years of children's lives, when conscious concern for proper development of the child makes parents actively involved in ensuring optimal conditions for the development and formation of a positive attitude towards health, physical activity and therefore limiting sedentary behaviors. In subsequent years of development, other factors are more prominent, including school and peers (Kirby, Levin, Inchley, 2011). Moreover, many studies show that the level of education is a part of a complex set of indicators that represent standards of living in the family and less frequently it is taken into consideration as an independent factor that influences PA and SB. It is possible that cultural diversity of comparable societies and interrelations of parental educational level with other factors of the socio-economic environment may influence the results. It is suggested that it is not the level of education that has a major influence on physical activity, but parents' support connected with high SES (Hoefer, Mckenzie, Sallis, Marshall, Conway, 2001). In regards to the lack of physical activity it is possible that its determinants are different to those for physical activity, and may be more socio-demographic in nature.

Preference to spend leisure in the family in an active way was a vital predicator for physical activity in both sexes, as well as sedentary behaviors in boys. Spending leisure time together with the family was a significant factor for physical activity. Our study confirmed earlier findings of other authors who emphasized the importance of family in shaping patterns of physical activity in children and adolescents, and also their sedentary behaviors (McGuire, Hannan, Neumark-Sztainer, Cossrow, Story, 2002; Welk, Wood, Morss, 2003; Biddle, Whitehead, O'Donowan, Nevill, 2005; Sukys, Majauskienè, Cesnaitiene, Karanauskiene, 2014). Family support for any forms of recreational exercises plays an important role in shaping health awareness and physical activity. While according to Social Learning Theory (Sallis, Nader, 1998), observation and parroting is very important in the case of younger children, in older children and adolescents direct and indirect influence of the physical, socio-economic, cultural, and sociocognitive aspects of the environments are more significant. It was proven that the support of sons and daughters differs considerably. Boys, in comparison with girls, receive more support regarding access to sports facilities and opportunities to take part in sports activities (Welk et al., 2003; Sallis, Nader, 1998). Parental support manifests 
itself also as transferring positive behavioral patterns. That is why children and adolescents from families where parents are more physically active are more supported and encouraged to higher physical activity, whereas children of parents who are less physically active are also less supported and encouraged. Sukys et al. (2014) pointed out that the influence of physical activity of parents is significant only in case of adolescents and concerns participation in sport. Such associations are particularly visible in girls (McGuire et al., 2002). Additionally, studies on Lithuanian adolescents emphasize quite a significant influence of at least one parent's physical activity on girls' physical activity, while an important predicator of PA in boys was the father's PA, especially in the age groups of 15-16 years old and 17-18 year old boys (Sukys et al., 2014). M.T. McGuire et al. (2002) found that even in younger adolescents (grades 7-10), the physical activity of parents and their attention to fitness not only positively associates with the physical activity of their children, but also negatively with the time devoted to watching TV. S.J.H. Biddle et al. (2005) pointed out that although there is an important positive influence of parental physical activity on the PA of adolescents of both sexes, other forms of parental support seem to be more significant. It appears that the key factor to adolescents' physical activity may also be family habits regarding the spending of leisure time. Although at puberty and maturation, adolescents usually spend time with their peers, spending leisure time with parents is still an important element of building close relationships. The lack of some important interrelations among girls may confirm that the influence of parents diminishes with age and the influence of peers increases (Larson, Richards, Moneta, Holmbeck, Duckett, 1996).

One must take into account that this study has several limitations. First of all, the data regards adolescents in the post-pubertal period and is cross-sectional. Consequently, it does not allow us to follow dynamic changes in physical activity or changes in interrelations of PA with indicators of the environment. The study did not take into account income per capita in the family. It seems that this factor may have a stronger influence on physical activity and sedentary behaviors than the level of education. The participants of the study came from one region of Poland, so the results do not necessarily apply to the whole population of Poland. A strong advantage of this study is the fact that it researched a large, randomly chosen group of people in a narrow age bracket. Although the evaluation of physical activity was subjective, its advantage is the fact that is not arduous for the participants of the study and therefore it does not influence their behavior. What is more, it allowed us to analyze total physical activity connected with all aspects of life. The advantage of IPAQ is a set of precise methodological rules that allows one to compare data from different countries and the officially registered Polish version of the questionnaire takes into account local conditions and specific aspects of the local way of life.

Findings regarding the influence of family background and the school environment on forming physical activity have a significant value since they allow one to introduce to Physical Education syllabuses programs that would increase health awareness in adolescents. They may also help in realizing small research projects in order to estimate the influence of additional physical exercise on the health of the persons studied. It is recommended to include in such projects adolescents, especially girls, in the period of their life when their identity and health awareness are being formed, as well as patterns associated with spending leisure time when the plasticity of the mind is still high and it is susceptible to the influence of adults. 


\section{Conclusions}

According to this study, the type of school the participants attended, the way of spending leisure time with the family, and in boys also spending leisure time together with the family, are the most important factors that influence physical activity and sedentary behaviors.

Future research should take into consideration the analysis of physical activity in separate domains. Evaluating physical activity only on the basis of total PA means that we oversee much important information about its structure, which can be helpful in designing efficient strategies that promote physical activity in different milieus and social groups.

\section{Acknowledgments}

Authors gratefully acknowledge and thank the adolescents who participated in this study. Authors also thank Świętokrzyskie Province Deputy Education Superintendent: Mr Grzegorz Bień, schools principals, and teachers for their commitment and support in the organization of the research.

\section{Financial support}

The project is supported under the program of Minister of Science and Higher Education under the name: 'Regional Initiative of Excellence in 2019-2020', project number 024/RID/2018/2019, financing amount: $11,999,000.00$ PLN.

\section{References}

Aarnio, M., Kujala, U.M., Kaprio, J. (1997). Associations of health-related behaviors, school type and health status to physical activity patterns in 16 year old boys and girls. Scand J Public Health, 25 (3), 156-167.

Aarnio, M., Winter, T., Kujala, U., Kaprio, J. (2002). Associations of health related behaviour, social relationships, and health status with persistent physical activity and inactivity: a study of Finnish adolescent twins. Br J Sports Med., 36 (5), 360-364.

Albarwani, S., Al-Hashmi, K., Al-Abri, M., Jaju, D., Hassan, M.O. (2009). Effects of overweight and leisure-time activities on aerobic fitness in urban and rural adolescents. Metab Syndr Relat Disord., 7 (4), 369-374.

Alderman, B.L., Benham-Deal, T.B., Jenkins, J.M. (2010). Change in parental influence on children's physical activity over time. Journal of Physical Activity \& Health, 7 (1), 60-67.

Árnadóttir, S.A. (2010). Physical activity, participation and self-rated health among older community-dwelling Icelanders. A population - based study. Umeå University Medical Dissertations, New Series, 361, 25-30.

Azevedo, M.R., Araújo, C.L., Reichert, F.F; Siqueira, F.V, Da Silva, M.C., Hallal, P.C. (2007). Gender differences in leisure-time physical activity. Int J Public Health, 52 (1), 8-15.

Badland, H., Schofield, G. (2006). Understanding the relationship between town size and physical activity levels: a population study. Health Place, 12 (4), 538-546.

Beets, M.W., Cardinal, B.J., Alderman, B.L. (2010). Parental social support and the physical activity-related behaviours of youth: a review. Health Educ Behav., 37 (5), 621-644.

Belcher, B.R., Berrigan, D., Dodd, K.W., Emken, B.A., Chou, C.P., Spuijt-Metz, D. (2010). Physical activity in US youth: impact of race/ ethnicity, age, gender, and weight status. Med Sci Sports Exerc., 42 (12), 2211-2221.

Bergier, B., Bergier, J., Paprzycki, P. (2014). Level and determinants of physical activity among school adolescents in Poland. Ann Agric Environ Med., 21 (1), 75-78.

Biddle, S.J.H., Whitehead, S.H., O'Donowan, T.M., Nevill, M.E. (2005). Correlates of participation in physical activity for adolescent girls: A systematic review of resent literature. J Phys Act Health, 2, 423-434. 
Bryant, A.L., Schulenberg, J., Bachman, J.G., O'Malley, P.M., Johnston, L.D. (2000). Understanding the links among school misbehavior, academic achievement, and cigarette use: a national panel study of adolescents. Prev Sci. 1 (2), 71-87.

Cadogan, S.L., Keane, E., Kearney, P.M. (2014). The effects of individual, family and environmental factors on physical activity levels in children: a cross-sectional study. BMC Pediatr. 14, 107. DOI:10.1186/1471-2431-14-107.

Craig, C.L., Marshall, A.L., Sjöström, M., Bauman, A.E., Booth, M.L., Ainsworth Be, Prat, M., Ekelund, U., Yngwe, A., Sallis, J.F., Oja, P. (2003). International physical activity questionnaire: 12-country reliability and validity. Med Sci Sports Exerc. 35 (8), 1381-1395.

Czapiński, J., Panek, T. (eds.) (2014). Diagnoza społeczna 2013. Warunki i jakość życia Polaków. Raport. Warszawa: MPiPS.

Davison, K.K., Lawson, K.T. (2006). Do attributes in the physical environment influence children's physical activity? A review of literature. Int J Behav Nutr Phys Act., 3, 19. DOI: 10.1186/1479-5868-3-19.

Delisle, T.T., Werch, C.E., Wong, A.H., Bian, H., Weiler, R. (2010). Relationship between frequency and intensity of physical activity and health behaviors of adolescents. J Sch Health, 80 (3), 130-140.

Echols, F.H., Willms, J.D. (1995). Reasons for school choice in Scotland. J Educ Policy, 10 (2), 143-156.

Elinder, L.S., Heinemans, N., Zeebari, Z., Patterson, E. (2014). Longitudinal changes in health behaviours and body weight among Swedish school children - associations with age, gender and parental education - the SCIP school cohort. BMC Public Health, 14, 640. DOI:10.1186/1471-2458-14-640.

Finger, J.D., Mensink, G.B.M., Banzer, W., Lampert, T., Tylleskär, T. (2014). Physical activity, aerobic fitness and parental socioeconomic position among adolescents: the German Health Interview and Examination Survey for children and adolescents 2003-2006 (KiGGS). Int J Behav Nutr Phys Act. 11 (1), 43. DOI: 10.1186/1479-5868-11-43.

Green, C.P., Navarro-Paniagua, M.,. Ximénez-De-Embún, D.P., Mancebón, M.J. (2014). School choice and student wellbeing. Econ Educ Rev. 38, 139-150.

Hill, N.E., Castellino, D.R., Lansford, J.E., Nowlin, P., Dodge, K.A., Bates, J.E., Pettit, G.S. (2004). Parent academic involvement as related to school behavior, achievement, and aspirations: demographic variations across adolescence. Child Dev., 75 (5), 1491-1509.

Hoefer, W.R., Mckenzie, T.L., Sallis, J.F., Marshall, S.J., Conway, T.L. (2001). Parental provision of transportation for adolescent physical activity. Am J Prev Med., 21 (1), 48-51.

Huang, S., Schnaub, M.P., Gross, C.S., John U., Mayer, C. (2013). Predictors of hazardous drinking, Tobacco smoking and physical inactivity in vocational school students. BMC Public Health, 13, 475. DOI: 10.1186/1471-2458-13-475.

http://ec.europa.eu/Eurostat (30.07.2017).

IPAQ: Guidelines for Data Processing and Analysis of the International Physical Activity Questionnaire (IPAQ) - Long Form, (2012). Retrieved from: http://www.ipaq.ki.se/scoring.pdf (14.03.2017).

Janssen, I., Leblanc, A.G. (2010). Systematic review of health benefits of physical activity and fitness in school-aged children and youth. Int J Behav Nutr Phys Act., 7, 40. DOI: 10.1186/1479-5868-7-40.

Jimenez-Pavon, D., Fernandez-Alvira, J.M., Te Velde, S.J., Brug, J., Bere, E., Jan, N., Kovacs, E., Androutsos, O., De Bourdeaudhuij, I., Moreno, L.A. (2012). Associations of parental education and parental physical activity (PA) with children's PA: The ENERGY cross-sectional study. Prev Med., 55 (4), 310-314.

Jodkowska, M., Oblacińska, A., Mikiel-Kostyra, K., Tabak, I. (2012). The frequency of risk factors for atherosclerosis in youth aged 16 and 18 years - students of upper-secondary schools in Poland. Dev Period Med., 16 (2), 96-103.

Jones, A.M., Rice, N., Dias, P.R. (2012). Quality of schooling and inequality of opportunity in health. Empire Economics, 42, 369-394.

Kantomaa, M.T., Tammelin, T.H., Näyhä, S., Taanila, A.M. (2007). Adolescents' physical activity to family income and parents education. Prev Med., 44 (5), 410-415.

Katzmarzyk, P.T., Baur, L.A., Blair, S.N., Lampert, E.V., Oppert, J.M., Riddoch, C. (2008). International conference on physical activity and obesity in children: summary statement and recommendation. Appl Physiol Nutr Metab., 33, 371-388.

Kirby, J., Levin, K.A., Inchley, J. (2011). Parental and peers influences on physical activity among Scottish adolescents: a longitudinal study. J Phys Act Health, 8 (6), 785-793.

Korzeniowska, E., Puchalski, K. (eds.) (2010). Nisko wykształceni pracownicy a zdrowie - wyzwania dla edukacji zdrowotnej. Projekt LEEECH. The Nofer Institute of Occupational Medicine. Retrieved from: http://www.imp.lodz.pl (5.05.2017).

Kristjansdottir, G., Vilhjalmsson, R. (2001). Sociodemographic differences in patterns of sedentary and physically active behavior in older children and adolescents. Acta Paediat., 90 (4), 429-435.

Lachowski S.,, Zagórski J. (2011). Child labour for the benefit of the family in rural Poland. Ann Agric Environ Med., 18 (2), 386-392. 
Lachowski, S. (2013). Health consequences of work in childhood in opinions of respondents from agricultural families. Ann Agric Environ Med., 20 (3), 624-630.

Larson, R.W., Richards, M.H., Moneta, G.B., Holmbeck, G., Duckett, E. (1996). Changes in adolescents' daily interactions with their families from ages 10 to 18: Disengagement and transformation. Dev Psychol., 32 (4), 744-754.

Lasheras, L., Aznar, S., Merino, B., Lopez, E.G. (2001). Factors associated with physical activity among Spanish youth through the National Health Survey. Prev Med., 32 (6), 455-465.

Loucaides, C.A., Jago, R., Theophanous, M. (2011). Physical activity and sedentary behaviours in Greek-Cypriot children and adolescents: a cross-sectional study. Int J Behav Nutr Phys Act., 19 (8), 90. DOI:10.1186/1479-5868-8-90.

Machado-Rodriques, A.M., Coelho-E-Silva, M.J., Mota, J., Padez, C., Martins, R.A., Cumming, S.P., Riddoch, C., Malina, R.M. (2014). Urban-rural contrast in fitness, physical activity, and sedentary behaviour in adolescents. Health Promot Int., 29 (1), 118-129.

McGuire, M.T., Hannan, P.J., Neumark-Sztainer, D., Cossrow, N.H., Story M. (2002). Parental correlates of physical activity in a racially/ ethnically diverse adolescent sample. J Adolesc Health, 30 (4), 253-261.

O'Connor, T.M., Jago, R., Baranowski, T. (2009). Engaging parents to increase youth physical activity a systematic review. Am J Prev Med., 37 (2), 141-149.

Owen, N., Sugiyama, T., Eakin, E.E., Gardiner, P.A., Tremblay, M.S., Sallis. J.F. (2011). Adults' sedentary behavior determinants and interventions. Am J Prev Med., 41 (2), 189-196.

Owens, C.S., Crone, D., James Dr. (2013). Physical activity and sedentary behavior among adolescents. In: A. Parker, D. Vinson (eds.), Youth sport, physical activity and play: policy, interpretation and participation (pp. 113-125) (1 ${ }^{\text {st }}$ ed.). New York: Roudledge.

Pate, R.R., Mitchell, J.A., Byun, W., Dowda, M. (2011). Sedentary behaviour in youth. Br J Sports Med., 45 (11), 906-913.

Reiner, M. (2013). Long-term health benefits of physical activity - a systematic review of longitudinal studies. BMC Public Health, 13, 813. DOI:10.1186/1471-2458-13-813.

ICSU (2011). Report of the ICSU Planning Group on Health and Wellbeing in the Changing Urban Environment: a Systems Analysis Approach. International Council for Science, Paris.

Sallis, J.F., Nader, P.R. (1998). Family Determinants Of Health Behaviors. In: D.S. Gochman (ed.), Health Behavior: Emerging Research Perspectives (pp. 107-124). New York: Plenum.

Solomon, E., Rees, T., Ukoumunne, O., Metcalf, B., Hillsdon M. (2013). Personal, social, and environmental correlates of physical activity in adults living in rural south-west England: a cross-sectional analysis. Int J Behav Nutr Phys Act., 10, 129. DOI:10.1186/1479-5868-10-129.

Springer, A.E., Hoelscher, D.M., Castrucci, B, Perez, A., Kelder, S.H. (2009). Prevalence of physical activity and sedentary behaviors by metropolitan status in 4th-, 8th, and 11-grade students in Texas, 2004-2005. Abstract. Prev Chronic Dis., 6 (1), A21. Retrieved from: http://www.cdc.gov/ pcd/issues/2009/jan/07_0252.htm (20.02.2016).

Statistical Yearbook, in Polish: Rocznik Statystyczny. (2013). GUS, Warszawa.

Sukys, S., Majauskienè, D., Cesnaitiene, V.J., Karanauskiene, D. (2014). Do parents' exercise habits predict 13-18-year-old adolescents' involvement in sport? J Sports Sci Med,. 13 (3), 522-528.

Suliga, E. (2010). Parental education and living environmental influence on physical development, nutritional habits as well as level of physical activity in Polish children and adolescents. Anthropol Anz., 68 (1), 53-66.

Tammelin, T., Näyhä, S., Laitinen, J., Rintamäki, H., Järvelin, M.R. (2003). Physical activity and social status in adolescence as predictors of physical inactivity in adulthood. Prev Med., 37 (4), 375-381.

Telama, R., Yang, X., Hirvensalo, M., Raitakari, O. (2006). Participation in organized youth sport as a predictor of adult physical activity: a 21 -year longitudinal study. Ped Exerc Sci., 17, 76-88.

Tremblay, M.S., Colley, R.C., Saunders, T.J., Healy, G.N., Owen, N. (2010). Physiological and health implications of a sedentary lifestyle. Appl Physiol Nutr Metab., 35 (6), 725-740.

Van Der Horst, K., Paw, M.J., Twisk, J.W.R., Van Mechelen. W. (2007). A brief correlates of physical activity and sedentariness in youth. Med Sci Sports Exerc., 39 (8), 1241-1250.

Van Der Horst, K., Oenena, A., Te Velde, S.J., Brug, J. (2009). Gender, ethnic and school type differences in overweight and energy balance - related behaviours among Dutch adolescents. Int J Ped Obes., 4 (4), 371-380.

Vašičková, J., Groffik, D., Frömel, K., Chmelík, F., Wasowicz, W. (2013). Determining gender differences in adolescent physical activity levels using IPAQ long form and pedometers. Ann Agric Environ Med., 20 (4), 749-755. 
Vlahov, D., Freudenberg, N., Proietti, F., Ompad, D., Quinn, A., Nandi, V., Galea, S. (2007). Urban as a determinant of health. J Urban Health, 84 (1), 16-26.

Vlahov, D., Galea, S. (2002). Urbanisation, urbanicity and health. J Urban Health, 79 (1), 1-12.

Welk, G., Wood, K., Morss, G. (2003). Parental influences on physical activity in children: an exploration of potential mechanisms. Pediatr Exerc Sci., 15 (1), 19-33.

Cite this article aS: Cieśla, E., Suliga, E. (2019). The Place of Living, School and Family Influence on the Pattern of Physical Activity and Sedentary Behavior of Adolescents: a Cross Sectional Study. Central European Journal of Sport Sciences and Medicine, 3 (27), 25-40. DOI: 10.18276/cej.2019.3-03. 